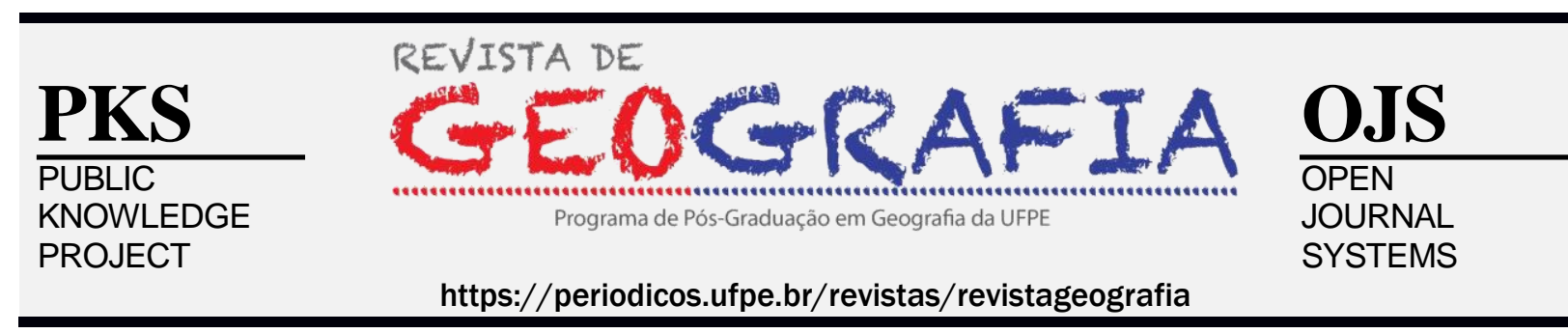

\title{
SERTÃO E LITORAL: POR UMA DISCUSSÃO PRELIMINAR DO SERTÃO NO PLANALTO CENTRAL
}

\author{
Arlete Mendes da Silva ${ }^{1}$, Hamilton Matos Cardoso Júnior ${ }^{2}$ \\ ${ }^{1}$ Universidade Estadual de Goiás - UEG. E-mail: etelra19@yahoo.com.br \\ ${ }^{2}$ Universidade Federal da Paraíba - UFPB.E-mail: hjuniorgo@hotmail.com
}

Artigo recebido em 18/07/18 e aceito em 16/09/18

\begin{abstract}
RESUMO
As relações existentes entre sertão e litoral podem ser apreendidas no processo de formação histórica de nosso país. Desde o inicio da colonização na América Portuguesa o sertão é visto como o limite, área longínqua. No entanto, o sertão agrega uma dinâmica econômica intensa. A mineração aurífera colonial, a agricultura de subsistência, o agronegócio, a indústria e o turismo surgem como atividades econômicas que integram sertão e litoral. Contudo, a análise do sertão vai além do econômico. Deve-se entendê-lo como lugar de vivência, de sentimento, de pertencimento e de experiência de seus sujeitos: os sertanejos. Atualmente, o sertão tem passado por intensas mudanças em seu espaço físico, em sua economia e na cultura de seus habitantes, que às vezes é transformada pela modernidade produtiva ou mantida pelos interesses dos agentes do capital turístico. Este trabalho tem como intuito realizar uma discussão preliminar sobre a dualidade entre o sertão e o litoral, apresentando como o sertão tem sido captado e incorporado pelo capital no decorrer da história, bem como ressaltar a importância de seu entendimento como lugar de vivência. O estudo apresenta-se no formato de uma pesquisa exploratória e qualitativa, utilizando como método a pesquisa bibliográfica.
\end{abstract}

Palavras-chave: Litoral. Sertanejos. Sertão. Vivência.

\section{HINTERLAND AND COAST: FOR A PRELIMINARY DISCUSSION OF THE HINTERLAND IN PLANALTO CENTRAL}

\begin{abstract}
The existing relations between hinterland and coastline can be seized in the historical formation process of our country. Since the beginning of colonization in Portuguese America the hinterland is seen as the limit, remote area. However, the hinterland adds an intense economic dynamics. Colonial gold mining, subsistence agriculture, agribusiness, industry and tourism arising as economic activities that integrate hinterland and coastline. However, the analysis of the hinterland goes beyond the economic. One must understand it as place of life, of feeling, of belonging and of experience of its subject: the sertanejo. Currently, the hinterland has undergone intense changes in your physical space, in its economy and culture of its inhabitants, which is sometimes transformed by productive modernity or maintained by the interests of agents of the tourist capital. Purpose of this study is to conduct a preliminary discussion on the duality between the hinterland an coastline, showing as the interior has been picked up and incorporated by capital in the course of history, as well as highlight the importance of understanding how living place. The study is presented in the form of an exploratory an qualitative research, using as method the bibliographical research.
\end{abstract}

Keywords: Coast. Rural Workers. Hinterland. Experience. 


\section{INTRODUÇÃO}

O trabalho se propõe a tecer uma reflexão acerca do sertão (oeste - interior) buscando sua contextualização histórica, abordagens conceituais e condições hodiernas que o envolvem, justificando seu status como objeto de estudo e inquietações.

A pretensão é refletir sobre o interesse no resgate de formas espaciais e temporais que contrapõe o modelo urbano pós-industrial que hoje se vivencia. Relacionar o sertão com seu conteúdo histórico (imaginário e/ou real) oportunizará a busca de suas identidades territoriais - num recorte espaço-temporal - que possibilite perceber sua presença (ou essência) numa aparente inexistência.

Uma analogia do sertão na perspectiva da relação cidade-campo pode conduzir ao imaginário coletivo de conceitos e preconceitos propondo, ainda, alusão à noção de "espaço" e "lugar" para diferentes culturas em diferentes espacialidades temporais. Construir ou reconhecer a importância histórica, social e cultural do que se chama de sertão é ir além de conceitos e teorias. É recompor um "mundo novo" que se mantenha alienado em relação a sua fundamental inserção regional e nacional em tempos pós-modernos.

Nesse sentido, aproxima-se do sertão como um espaço particularizado e singular, que agrupa um povo de identidade cultural. Buscar-se analisá-lo como um território de dinamicidade histórica, a qual participa os sentimentos, a noção de pertencimento e a noção de ocupar um lugar no mundo.

O artigo utiliza como recorte espacial o sertão do Planalto Central do Brasil. Parte-se a uma análise das principais transformações em curso nessa região, tecendo reflexões de como sua incorporação pelo sistema produtivo capitalista tem alterado o cotidiano de seus sujeitos: os sertanejos.

O trabalho divide-se em cinco seções a contar com esta introdução. Nesse sentindo, na segunda seção realiza uma discussão sobre a condição do sertão e dos povos que vivem nesse espaço, bem como da dinâmica histórico geográfica na formação territorial do sertão no Planalto Central; a terceira seção procura refletir sobre a dialética presente entre o sertão e o litoral; a quarta seção busca ponderar sobre as mudanças contemporâneas que impactam o sertão nessa região, refletindo sobre a expansão do agronegócio e, principalmente, da presença do turismo rural. Por fim, na quinta e última seção realiza algumas considerações finais a respeito dessa temática. 


\section{SERTÃO E SUA CONDIÇÃO EM SER SERTÃO}

O termo sertão pode ser entendido como uma zona de transição entre "terra civilizada" e "mata virgem" podendo ser classificado por estágios e/ou tipos de fronteira que pode ser demográfica, econômica e/ou política, justifica Leo Waibel (1979, p. 281). Contudo, a abrangência do sertão vai além de suas características físicas e econômicas alcançando também os sujeitos que nele vivem: os sertanejos.

A discussão quanto ao sertão e litoral, no Brasil, regressa à colonização portuguesa na América. Pode-se evidenciar este fato citando as palavras de Frei Vicente Salvador (1627) ao apontar que a colonização lusitana havia ganhado caráter litorâneo: “[...] da largura que a terra do Brasil tem para o sertão [...] até agora não houve quem a andasse, por negligencia dos portugueses que, sendo grandes conquistadores de terras, não se aproveitam delas, mas concentram-se as andar arranhando ao longo do mar como caranguejos" (BRASIL, 2014, p. $5)$.

O sertão do Brasil central, palco das febris descobertas auríferas e do nascimento de uma sociedade opulenta e desordenada pela mineração, como evidenciou Palacin (1994), despacha à dinâmica de sua história como meio para entender a construção da identidade dos atuais estados que o ocupam e que foi construída frente a diversas diferenças físicas, econômicas e sociais.

Esse entendimento fez-se, principalmente, no contexto do período aurífero (século XVIII) e das zonas pioneiras que desbravaram o interior brasileiro. Na região Centro-Oeste as zonas pioneiras evoluíram após a I Guerra Mundial, tendo como função a produção de gêneros alimentícios para o mercado interno, obtendo posterior importância para o mercado internacional. Daí ser o "sertanejo" conhecido também como "pioneiro".

Esse sertão de passagem (ou de chegada dos pioneiros/migrantes) já vivenciou épocas de glórias e desenganos no sentido socioeconômico. Acontecidas as primeiras explorações em território sertanejo, datadas do século XVII para o século XVIII, pelos bandeirantes paulistas a procura de índios e pedras preciosas, foram surgindo as primeiras formas de organização e produção espacial proporcionada pela atividade mineradora.

Foi sob as chamadas bandeiras paulistas ${ }^{1}$ que colonos da região de São Vicente, atual estado de São Paulo, adentraram o vasto sertão da colônia. Essas bandeiras partiram

\footnotetext{
${ }^{1}$ As bandeiras eram empresas privadas constituídas com base num sistema de ações, onde cada bandeirante tinha direito ao recebimento dos lucros de acordo com seu investimento (PALACIN, 1994).
} 
especialmente durante o século XVII e duravam por meses e até mesmo anos. Seu principal objetivo era a captura de índios que seriam vendidos no mercado comercial de escravos. Sobre essas expedições Fausto (1996) ressalta que:

As bandeiras tomaram as direções de Minas Gerais, Goiás, Mato Grosso e as regiões onde se localizavam as aldeias de índios guaranis organizadas pelos jesuítas espanhóis. Algumas bandeiras realizaram imensas viagens, em que a atração por uma grande aventura se mesclava com objetivos econômicos. Já veterano, Raposo Tavares percorreu, entre 1648 e 1652, um roteiro de 12 mil quilômetros [...]. (FAUSTO, 1996, p. 59).

Assim, "graças” às bandeiras paulistas, surgem as primeiras descobertas significativas de ouro no interior da colônia. A data oficial dos primeiros descobrimentos é intensamente discutida entre historiadores, porém há um consenso que se situaram nas últimas décadas do século XVII. Sobre esse fato, Fausto (1996) salienta que:

Em 1695, no Rio das Velhas, próximo às atuais Sabará e Caeté, ocorreram as primeiras descobertas significativas de ouro. A tradição associa a essas primeiras descobertas o nome de Borba Gato, genro de Fernão Dias. Durante os quarenta anos seguintes, foi encontrado ouro em Minas Gerais, na Bahia, Goiás e Mato Grosso. Ao lado do ouro, surgiram os diamantes, cuja importância econômica foi menor, descobertos no Serro Frio, norte de Minas, por volta de 1730 (FAUSTO, 1996, p. $60)$.

Anteriormente aos achados de ouro em Goiás, e posteriormente à descoberta de ouro em Minas Gerais, “[...] em 1719, nas remotíssimas paragens de Mato Grosso, jazidas tão ricas que [...] o ouro se retirava da terra como a nata do leite" (PALACIN, 1994, p. 14) foram encontradas em Cuiabá. Com seu território situando entre Minas, São Paulo e Mato Grosso, as esperanças e sonhos de haver ouro no centro da colônia, em Goiás, acenderam-se ainda mais.

As descobertas em Goiás são datadas em 1725. Após uma excursão de três anos e três meses de viagem, a Bandeira denominada de Anhanguera, retorna a São Paulo com a notícia do descobrimento das tão procuradas minas em Goiás. Nasce o novo eldorado da colônia e uma nova e febril migração origina-se, só que dessa vez adentrando ainda mais o vasto sertão. Com a descoberta das minas em Goiás, a região central da colônia tronou-se o centro aurífero do reino, concentrando a maior densidade aurífera, que ia de Minas Gerais a Mato Grosso.

É importante ressaltar, como mostram Gomes, Neto e Barbosa (2004), que o território goiano-tocantinense atual foi constituído sobre antigos territórios de povos e tribos indígenas e que a configuração institucional do território atual que se conhece é resultado de \begin{tabular}{lcr} 
intensas mudanças ocorridas num período de mais de 200 anos. Do mesmo modo os \\
\hline Silva e Cardoso Júnior, 2019. & ISSN 0104-5490 & 157
\end{tabular} 
territórios de Minas Gerais; de Mato Grosso e Mato Grosso do Sul. Nesse sentido, afirma-se consoante a Moraes (2002), que o território é resultado de um processo lento, histórico e pluricelular. O processo de formação do território é dinâmico e não estático. É resultado de diversas transformações (incorporações, fragmentações, demarcações e nomeações) históricas.

A de se relatar aqui o sentimento de superioridade do litoral sobre o sertão desde a época das descobertas auríferas, fato ainda reforçado. Como aponta Fausto (1996), a figura do paulista, "litorâneo", foi exaltada por historiadores de São Paulo como Alfredo Ellis Junior, com o título de sua obra "A Raça de Gigantes", e Afonso Tauany, que escreveram suas obras na primeira metade do século XX. "Tudo não passava de fantasias com pretensões científicas" (FAUSTO, 1996, p. 59). Entretanto, são análises que se reforçam e que perduram até os dias de hoje.

A ocupação do sertão no Planalto Central, levando em consideração sua elevada importância para a colônia, sendo o "coração pulsante" que mantinha o reino de pé, fez com que a Coroa Portuguesa sentisse a necessidade de conhecer e controlar suas novas possessões, ou seja. Roteiros e mapas foram produzidos, marcando caminhos e rotas de minas, sendo o sertão submetido ao "ordenamento", à medição e à delimitação.

A pecuária, que seguia paralela aos núcleos de extração aurífera colonial, também foi elemento que contribuiu para a ocupação e formação territorial do sertão. Assim, grandes fazendas surgem pelos caminhos dos tropeiros tangendo o gado e também pela rudimentar atividade comercial. Com a exploração e a fixação do homem por essas terras, inicia-se o processo de colonização no Centro-Oeste pelo capital, já no século XIX, intensificada no século XX. A pecuária já anunciava a necessidade de buscar novas áreas para desenvolver suas atividades.

A agricultura se expande após a Lei de Terras em 1850. A terra passa a ter valor e se torna mercadoria inserida no modelo capitalista de produção. A “terra-mercadoria" expropria, produz e transforma a vida no sertão. No contexto de ocupação e regionalização do sertão no Planalto Central algumas áreas (com maior desenvolvimento econômico) ganhavam importância em detrimento de outras que, afetadas pelas ríspidas condições naturais, já exercia papel secundário na configuração espacial da região.

A industrialização no sudeste e a "valorização do extremo oeste do Brasil" fez consolidar a necessidade da Marcha para o Oeste, defendida pelos governantes dadas à luta pelo desenvolvimento e integração nacional. O cerrado goiano sofreu fortes transformações 
sob a gestão capitalista voltada para a produção e comercialização de produtos, assim como o sertão mato-grossense que sofreu importantes interferências em sua infraestrutura pela Fundação Brasil Central, como mostra Maciel (2012).

O que se verificou, na prática, foi a instauração de uma estrutura fundiária concentrada, expulsão do homem do campo (quando o trabalhador rural é trocado pela máquina) na forma de migração campo-cidade ou migrações regionais quando se busca novas terras mais longínquas: novas fronteiras em outros sertões.

De forma semelhante, Perdigão e Bassegio (1992) apontam que o sertanejo é incorporado à trajetória da constante "migração da ilusão". Isso porque a migração representa, para o trabalhador do campo, a possibilidade de terra para plantar, sobreviver e reproduzir seu modo de vida. Assim, a cada nova fronteira "aberta" nos confins do sertão há a mobilidade do homem do campo que migra em busca de futuro melhor.

Esse processo, nas palavras de Waibel (1979, p. 309), faz criar “[...] um novo sertão e uma nova leva de caboclos. Não se pode chamar a isto de uma marcha para o oeste". Este mesmo autor acreditava em um "verdadeiro camponês" como sendo o sertanejo que tivesse a posse da terra e pudesse construir ali seu lugar, mesmo sendo este sobre as bases do sertão.

Esse novo sertão, hoje globalizado pelo capital agroindustrial, principalmente, é alvo de ideologias capitalistas que justificam sua ocupação, por mais levianas que sejam. Como mostra Costa (1996), as geometrias lineares e uniformes da agroindústria presentes nas imensas plantações, rasgam o sertão suavizando as "rugas" do cerrado através de uma verdadeira "operação plástica", como se a beleza do cerrado fosse inferior à ditadura verde dos campos agrícolas.

Desse modo, verifica-se que a identidade do sertanejo se fez através do processo formador do território de origem. Esse processo histórico e dinâmico serviu-se de transformações econômicas, políticas e socioespaciais e de um complexo entretecimento cultural do sertanejo. Pensar o sertão central do Brasil é buscar tratar de sua constituição como espaço particularizado, singularizado e unificado. É entender e refletir sobre a existência de povos com identidade cultural. Não menos importante, é ressaltar seu território, territorialidade e os elementos que nele circundam: sentimentos de pertencimento, instituição do ser e estar no mundo e a consciência do ser sertanejo. 


\section{SERTÃO X LITORAL: DIALÉTICA REAL OU ANUNCIADA?}

Também compreendida contraditoriamente na formação sertão - litoral nota-se as contradições de espaços e tempos diferenciados dentro de um mesmo Estado-Nação, cujas divergências perpassavam condições econômicas, sociais e culturais. O litoral rico e desenvolvido - presente na história! O sertão pobre e desamparado vivendo à mercê da rudeza do clima e das inóspitas condições naturais - esquecido da história!

Com propósitos nacionalistas em se construir "outro Brasil" incorporando o sertão, Candice Vidal e Souza (1997) trabalha a contramão dessa história em uma obra primorosa "A pátria geográfica: sertão e litoral no pensamento social brasileiro" quando reflete sobre a incorporação do sertão no processo de construção de outro Brasil. Esse trabalho ampara pensar o sertão numa categoria de análise sertão-litoral para procurar entender o que significa o sertão num contexto socioeconômico atual com implicações culturais.

De um lado o sertão antiquado; do outro o litoral em plena marcha para a modernidade. Duas sociedades totalmente diferentes que reforçavam as fraturas no sentimento de nacionalidade do país no fim do século XIX e inicio do século XX. Sentimento, como mostra Murari (2007), que elucidavam as questões dos estudiosos do período à procura de reforçar a necessidade da identidade e da unidade nacional.

Souza (1997) realiza suas ponderações com base na obra de Euclides da Cunha "Os Sertões" (1902) entre outros pensadores da sociografia brasileira, em que se busca compreender e valorar o sertão como um lugar de vivência, de acontecimentos e de possibilidades: o acontecer da história! Seu objetivo visava unir as partes sertão-litoral evidenciando suas fragilidades e potencialidades que poderiam trazer equilíbrio, homogeneidade, sincronia e unidade nacional. Na percepção euclidiana (apud SOUZA, 1997, p. 104):

\footnotetext{
A fórmula regenerativa para a nacionalidade imperfeita vai buscar nos lugares de sertão a matéria-prima para se fazer outro país. O palpite de que lá nos interiores se guarda o substrato do Brasil ideal mostra-se com a constatação de que além, muito longe daquelas alvas praias arenosas, existe um mundo ignoto, mas cheio de excelências, e outra gente, não polida, mas sobremaneira varonil, inculta, mas generosa, necessária esta e imprescindível aquele à realidade brasileira.
}

Frente ao "projeto-nação", pretende-se que o Brasil seja uno: nem sertão, nem litoral. É assim que se reproduzia a ideologia pela Marcha para o Oeste a fim de criar um "território" homogêneo controlado pelo Estado. Ao "mundo sertanejo" tido como débil, frágil e atrasado caberia a mudança, de uma só vez, de seus “[...] costumes, mentalidades e modo de vida, além

Silva e Cardoso Júnior, $2019 . \quad$ ISSN 0104-5490 160


de modificar a aspereza da terra bruta e deserta. Há em tudo o propósito de disciplinar, pelo uso econômico e pela dependência governamental a terra e a gente desse lugar um dia selvagem, retardatário e insurgente" (SOUZA, 1997, p. 117). O sertão teria que aguardar e esperar a "civilização" para que seus "resíduos" não impedissem o sentido de unidade nacional.

Em sua análise, Murari (2007) mostra que as nações não passam de ficções percoladas no imaginário social. Ficções que são corolárias dos simbolismos que expressam a "unidade" nacional, e agem "unindo" a nação, identificando e "aproximando", nesse caso, o sertão e o litoral. No entanto, vale ressaltar que os símbolos que trazem a unidade não partem do sertão para o litoral, mas sim no inverso.

A apropriação do sertão pelo capital global atualmente é a repetição da história desde a penetração dos bandeirantes no período colonial, entretanto sob "novos modelos" penetração e "aproveitamento" do "sertão rico e deserto". Souza (1997, p. 126), citando Alberto Rangel, explicita que: "Felizmente o sertão [...] é o grande excitador da energia nacional [...]. É o estímulo da nação, que nada tem a conquistar lá fora. É o problema nacional por excelência". Ainda acrescenta que o sertão é “[...] como um relicário que curiosamente conserva o passado e o futuro daquilo que faz nosso sentido de Pátria” (idem).

Compreender, estudar e sentir o sertão não é tarefa fácil, entretanto, Brandão (1995) soube retratá-lo com muita propriedade utilizando a história oral de pessoas que conheciam e vivenciaram o lugar sertão. Carregadas de subjetividade e características míticas as informações passavam a ter "corpo" numa imagem que aos poucos se concretizava de acordo com a realidade vivenciada dos entrevistados. Assim, o autor (1995 p. 155-59) condensa que o sertão é:

- Área ou região oposta ao litoral;

- Lugar de absoluta natureza, por onde se passa, sem se morar;

- Lugar de bichos selvagens, índios e sertanejos (seres humanos civilizados, mas não plenamente socializados);

- Não possui nome específico e lhe é atribuído acidentes da natureza; e ainda

- Foi durante muito tempo lugar de produção para complemento da subsistência familiar.

\footnotetext{
2 "Novos modelos" aqui entendidos como estratégias governamentais atuais para alcançar/explorar o sertão através de planos de integração e/ou econômicos (de mercado). 
Percebe-se a "mudança de lugar" do sertão à medida que: "A cidade invade o campo e o campo invade o sertão através de novos personagens" (BRANDÃO, 1995, p. 170). Os sertões cercavam e agora recuam numa demonstração da ressignificação do lugar e a incorporação de novos espaços. Para Tuan (1983) essa situação reflete a relação de opostos ${ }^{3}$. O sertão é vivido como um lugar - espaço distante do litoral. E esse lugar dos "de dentro" vem se transformando em "não lugar" pelas ameaças vindas de fora. Ou seja, a urbanização do campo, a contínua mecanização agrícola, a diversificação do trabalho e da produção rural e a expulsão dos sertanejos para outras áreas / regiões mais distantes (do litoral), muitas vezes, por planos de gestão regional visando integração econômica.

Esse processo modifica o status do sertão para o sertanejo que vê seu lugar modificado por eventos externos que os obriga a migrar e construir um novo lugar, um novo sertão para a reprodução sociocultural sertaneja. Nesse sentido, há a possibilidade de existência de "novos e outros sertões" com novos sentidos de lugar pelos "de dentro" devido aos constantes movimentos de reconfiguração socioespacial.

Vale ressaltar de que lugar se fala quando é contextualizado o espaço do sertão e do sertanejo. Pelo olhar aguçado e perceptivo da Geografia Cultural, destacam-se reflexões que auxiliam nessa análise. Os autores souberam expressar com criatividade concernente ao povo sertanejo de tantos sertões que foram modernizados e urbanizados e outros, distantes, próximos ao campo e a natureza de onde também fazem parte como um mosaico de elementos naturais e humanos que se complementam e se refazem com novos significados.

Santos e Mendonça souberam descrever a alma do lugar representado pelas pessoas ali nascidas, no sertão. Ainda, fazendo uso da historicidade sertaneja e de seus ricos personagens, acompanha-se o raciocínio que compreende as humanidades do sertão como uma gente que construiu e organizou seu território com formas de existência não distantes dos “conflitos e interesses avessos". Esse povo, desde há muito, luta "com a mesma força que usaram para desbravar novas terras e outros sertões construindo suas territorialidades e um modus vivendi harmônico" e equilibrado (SANTOS; MENDONÇA, 2009, p. 10-11).

A construção histórica e espacial das gentes sertanejas se deparou, de repente, com fortes ventos de modernização no campo pelo crivo do capital moderno, competitivo e comercial. As estratégias de expansão dos processos produtivos dos planos governamentais

\footnotetext{
${ }^{3} \mathrm{Yi}-\mathrm{Fu}$ Tuan (1983) compreende o espaço configurado por porções do ambiente, frações de uma extensão de terra passíveis de serem transformadas em lugar mediante trabalho motivado de uso, ocupação e, sobretudo, de significação social. 
estenderam seus tentáculos até a região dos sertões promovendo mutações sociais e espaciais ainda não vistas em escala regional.

Parafraseando os autores, foi negado ao povo do sertão sua "legitimidade e historicidade" por eles constituídas ao longo dos anos. Chaveiro (2008, p. 90) contribui com essa discussão ao lembrar que a cultura desses povos não passou despercebida pela voracidade do capital e do lucro na capacidade de transformar "tudo" em mercadoria:

[...] Além disso, os saberes tradicionais, os componentes da memória, o patrimônio imaterial, os saberes diversos, modos de cantar, de falar, a memória arquitetônica, as diferentes identidades etc., colocam a cultura na rota da comercialização. Nessa vertente, o simples, o puro, o natural, o que é antigo etc., são mirados pelo olho da câmera, assim como festas, rostos, memórias, de modo que o processo mercantil age na pele, no cabelo, no trabalho e no inconsciente. Mercantilizam-se o visível e o invisível, o presente e o passado.

O olhar atento do autor traz clareza e senso crítico à discussão. Nesse espectro mercadológico e mercantilizado, os bens do sertão - mercadoria tem "compradô" certo, "ao gosto do freguês". Nesse modelo capitalista de tudo "vender" e comercializar entram a natureza, os animais, às formas humanas materiais e imateriais, os símbolos, as representações, a cultura e o sertanejo.

Os homens e mulheres do sertão sentem, "na pele", o prenúncio de um tempo outro, não da roça e do tempo gasto tangendo o gado, mas o da máquina, do lucro e da mercadoria. E, “à medida que o espaço é invadido por outros sujeitos e por propósitos de uso econômico, os signos vão mudando, bem como o tempo do espaço, o sentido que se dá à natureza e aos seus elementos" (CHAVEIRO, 2008, p. 92). Esses povos do sertão travam, já algum tempo, num movimento contraditório em relação ao lugar vivido, árdua batalha pelo direito de ser, possuir e continuar no sertão como sertanejos que são.

Num momento de perturbação, o prenúncio de uma resiliência ou resistência se anuncia quando, mesmo com a chegada do "outro", do capital, esse valente continua no lugar vivido. Como? O que o alimenta? Como resiste? Por certo, o espaço é um alimento que se sustenta do passado, pela história, pelos resíduos humanos nele construídos e depositados. Assim, podem estar no espaço e nos elementos que o compõe a fonte de sobrevivência dos sertões, dos sujeitos locais, que a ele (espaço-lugar) retorna nas horas de necessidade e crise.

Nesse retornar ao passado, procura-se algo inquestionável, legitimador e que vem à tona como uma medida de reconstrução ou de invenção de identidades que querem, além do reconhecimento, atingir uma coletividade que passe a defender, reconhecer, legitimar e fortalecer os vínculos de cada grupo (SANTOS 2008 p. 105). 
Pode-se inferir que o espírito aguerrido do sertanejo indique a rota de fuga, o caminho para a liberdade que não está fora do sujeito e nem do lugar, mas está dentro de cada 'ser'. Como proposta no entardecer dessa reflexão, sugere-se que as políticas públicas incluam os sertanejos nas discussões que envolvem ações de desenvolvimento dos sertões. Pelo menos como "desculpa verdadeira" para uma gestão dessa região com base nos princípios de desenvolvimento falseados como local e endógeno.

Todavia, a população sertaneja como outras comunidades que estão à margem do poder, não tem sido "enxergadas" e distantes estão do cerne das pautas políticas dos atores hegemônicos que arquitetam e executam grandes projetos. Nesse "governar e legislar" não se realizam estudos técnicos sobre efeitos impactantes no espaço e no modo de vida das pessoas do lugar, como também no tempo do seu movimento para inserção de grandes eventos ou projetos.

Concomitantemente, para os povos do sertão continuam existindo memórias, lembranças, representações, signos e símbolos mantendo sua identidade no ou fora do seu lugar. São sentimentos que remetem ao lugar vivido de um lugar passado distante ou próximo no tempo que se associa ao que aponta Massey (2009) sobre a saudade de um espaço, de um lugar, de um tempo! O espaço da casa, do lar, a saudade do migrante, do viajante, do desterrado (desterritorializado) do capital.

Nostalgia, perda, abandono, lembranças do lugar, do lar, da "minha casa"! São sentimentos que, muitas vezes, os sujeitos do campo (do sertão) tiveram de apreender com a incorporação do projeto de modernidade (ou pós-modernidade), independente de sua vontade ou escolha (principalmente pela grande massa de trabalhadores rurais).

Em sentido equivalente, Massey argumenta sobre a nostalgia pós-moderna que se projeta com a necessidade política de gestão socioespacial (e mercadológica) que se volta para a noção de espaço e tempo como forma de recuperação das necessidades afetivas e da natureza, importante para o equilíbrio biossocial (não seria este um forte mote do marketing turístico do momento atual?). Que ironia da história que ora se presencia! Mas, já não era sem tempo num tempo em que tudo se esvai como poeiras de tempos, espaços e cultura!

\footnotetext{
Minha questão é que a imaginação de voltar para casa significa, tantas vezes, 'voltar' tanto no tempo quanto no espaço. Voltar para as antigas coisas familiares, para o modo com que as coisas costumavam ser [...] as coisas que relembro do passado (MASSEY, 2009 p. 182).
}

Dessa forma é possível perceber que o lugar do sertão modifica à medida que esse espaço deixa de cercar e recua pela pressão de novos agentes, novos personagens. Assim, as 
palavras de Souza (1997) acomodam-se perfeitamente na nova realidade do sertão, esse que está sendo preservado no imaginário das experiências das pessoas e, contrariamente, não sendo mantido no imaginário e na experiência das pessoas. Daí chamarmos de Sertão mais do que o um lugar distante do litoral. O sertão, para além do espaço físico, tem na cultura sertaneja seu cerne e forma de existir. Desse modo, pode-se dizer da existência de dois tipos de sertão: sertão concreto, físico com seus elementos naturais e o sertão cultural que existe pela cultura e modos de vida do sertanejo.

"Todos os territórios vividos e/ou pensados os são através de categorias que de alguma maneira podem ser atribuídos também a outras dimensões naturais e/ou sociais de seres, coisas e situações da experiência relacional da vida" (BRANDÃO 1995 p. 171). Para o sertanejo o sertão é o seu lugar, seu mundo vivido e experienciado pelas relações naturais e sociais. Para o Estado o "[...] sertão que interessa é aquele de que se pode retirar alimento material e espiritual para a nação [...]" (SOUZA, 1997 p. 127).

\section{O “NOVO SERTÃO” NA CONTEMPORANDEIDADE: A RESSIGNIFICAÇÃO DO RECONHECIMENTO DOS ESPAÇOS RURAIS}

Procurando adequar os termos que, a priori, parecem dissonantes, discute-se o sertão no contexto do "urbano-rural", fazendo analogia ao "litoral-interior". É bem verdade que respeitadas às diferenças e configurações espaço-temporal, busca-se enfocar a relação cidadecampo e/ou urbano-rural no processo atual das atividades humanas e estas com vistas ao turismo que se coloca em nossos dias como importante direcionador econômico, social, cultural e de políticas públicas.

Nessa perspectiva, compreende-se o sertão em sua forma distante / longínqua / de interior de espaço rural - sertão - contracenando com o modus vivendi da cidade: espaço urbano. Em Goiás, como também no Brasil, há um momento de reconhecimento de espaços e de lugares. Uma atração pelo novo coloca em foco antigos lugares que já foram antes região de fronteira, sertão, pequenos aglomerados urbanos. Espaços com realidades objetivas e com produto social em permanente processo de transformação em seu tempo e espaço, mas que pode ser lócus agregador de valor e difusor cultural via políticas públicas e incremento de capital e logística. 
Fala-se em "espaços futuros” os quais Cassiano Ricardo 4 já alardeava ser o motor da expansão e colonização interna, um prosperar por dentro! E é nesse sentido que o turismo rural vem construindo e reconhecendo tais espaços rurais, como viés de desenvolvimento socioeconômico para o país com base local e endógeno. Vale ressaltar que essas estratégias, de forma explícita, visam o desenvolvimento do sertão rural e do sertanejo. No entanto, é o capital turístico e urbano que se apropria do espaço e do lucro gerado por essa atividade em espaço rural.

Portanto, o Brasil não possui sua área rural restringida às atividades agropecuárias. Nos últimos anos o meio rural vem ganhando novas funções e oportunidades de trabalho e renda para as famílias. A agropecuária moderna e a agricultura de subsistência dividem espaço com um conjunto de atividades ligadas ao lazer, prestação de serviço e indústrias.

As atividades de lazer em espaço rural possuem conotação histórica desde os antigos “caipiras" aos trabalhadores do campo hoje. O lazer estava impresso na cultura caipira que, segundo Cândido (1974), por não possuírem a posse da terra e pela falta de estímulos existia larga margem de lazer que funcionava como equilíbrio biossocial. Parte integrante da cultura caipira, as atividades de lazer podiam ser vistas em cooperações com a vizinhança (mutirões), festas, celebrações e na lida diária como a caça, pesca, coleta, artesanato e outras atividades da cultura humana material local. O autor adverte, porém, sobre os perigos a que estão expostas estas culturas, pois qualquer alteração vinda de fora provocaria sua mudança que seria seu próprio fim consoante à fragilidade em se manter sob forma própria de ajustamento ecológico e social.

Não obstante, as atividades rurais representarem hoje uma reafirmação cultural no desenvolvimento da atividade turística que objetiva o resgate, a preservação e a valorização da cultura em sua forma original, também, essa mesma atividade é fonte da ganância, do lucro, do uso e abuso do capital sobre o espaço rural e as pessoas que nele vive. Bem se sabe que a cultura não é o ato de tratar e fertilizar a terra e dar condições para o nascimento e desenvolvimento de plantas, mas sim o complexo padrão de comportamento, das crenças, das instituições e de outros valores transmitidos coletivamente, típicos de uma sociedade. É essa cultura uma das matrizes do turismo rural e da inserção de atividades rurais como elementos do promissor crescimento interno (e para dentro), mesmo servindo a outros propósitos menos altruístas.

\footnotetext{
${ }^{4}$ Cassiano Ricardo Leite (São José dos Campos, 26 de julho de 1894 — Rio de Janeiro, 14 de janeiro de 1974) foi um jornalista, poeta e ensaísta brasileiro.
} 
Relacionar o sertão com o meio rural é reconhecer especificidades que lhes caracterizam. O sertão está sempre nos confins, nas áreas limites, fronteiriças que podem ser alcançadas e traspassadas; lugar onde se extrai riquezas, novas possibilidades e áreas de reservas. Hoje o meio rural é este sertão híbrido onde as necessidades urbanas buscam favorecimentos não só econômicos, mas também socioculturais e espirituais, como advoga o marketing do turismo rural.

Relativo a esse turismo, é como se fosse uma inversão da importância do espaço. Antes o urbano por motivos econômicos, de "modernidade", de tecnologia e de "prosperidade", ideologias que sustentavam o êxodo rural. Hoje, o rural por motivos de qualidade de vida, de ar puro, de descanso e aliviamento do estresse.

A função rural é, historicamente, servir o urbano, o mesmo ocorrendo com o sertão e o litoral. As propostas e alternativas que se abrem, em tempos de pós-modernidade, pode auferir ao sertão/meio rural um status no contexto nacional onde o construir e o reconhecer sobrepõe o modelo de importação e alienação produtiva habitual.

Para não concluir questiona-se: seria, ainda, o rural e o sertão "espaços futuros" para apropriações capitalistas no contexto globalizador e globalizante tecendo novos processos espaciais? Esses processos estariam travestidos pela re-funcionalização que objetiva alimentar o mercado e o consumo ou evidência um movimento retrô de valorização socioespacial do sertão interior sem dicotomia com o litoral?

\section{CONSIDERAÇÕES FINAIS}

Analisar o sertão corresponde a ir além de suas características econômicas, alcançando os sujeitos que nesse espaço vivem. Suas questões não pertencem ao hoje. Apesar de atualmente possuírem outro caráter, as questões referentes ao sertão brasileiro, seja do Brasil Central ou outros, são históricas e dinâmicas.

Essas analogias e modos de pensar dão conta de que espaços e tempos não ficam "parados", estáticos, sem movimento. Eles continuam seu ritmo na sequência da existência humana e da natureza. Mesmo após a migração forçada - do campo para a cidade, da cidade rural para outras cidades -, a saída dos sujeitos estima lembranças de como eram esses lugares. No entanto, tem-se, por certo, a incerteza de que quando (e se) voltar ao lugar, nada será como antes! 
Nesse movimento / processo de retorno, sob quais signos a memória seria evocada, ou ainda, quais lembranças teriam permanecido? E as representações desse espaço, como seriam (re)construídas? São versos que confirmam conjecturas feitas por Massey (2009) sobre a saudade de um espaço, de um lugar, de um tempo! O 'espaço de casa, do lar', a saudade do migrante, do viajante, no 'desterrado' e do sertanejo. Nostalgia, perda, abandono, lembranças... do lugar, do lar, da 'minha casa'!

São sentimentos que, muitas vezes, os sujeitos (comunidades rurais tradicionais) tiverem de apreender com a 'incorporação ao projeto da modernidade' (ou pós modernidade). A autora argumenta sobre a 'nostalgia pós-moderna' que se projeta numa necessidade política de gestão socioespacial voltada para as noções de espaço e tempo como forma de recuperação da necessidade afetiva, importante para o equilíbrio bio-social.

Sob a opulência das minas, o sertão foi demarcado, nomeado, mapeado e submetido ao ordenamento territorial.O sertão é invadido pelos novos métodos de uso do solo, já no século XX, implantados pela agroindústria sedenta em colonizar as regiões interioranas. Desde então, o sertão vem sendo constantemente inserido no sistema de produção capitalista, produzindo expropriação e modificação na vida de quem vive no sertão. As ações protagonizadas pelo novo sistema de produção tiveram o Estado como mediador, à medida que atuava com os projetos de integração e interiorização.

A dialética existente entre o sertão-litoral anuncia-se nos discursos de cunho econômico, político e social: sustenta-se nos discursos a existência de um sertão pobre e atrasado, e um litoral rico e desenvolvido. O sertanejo concebe o sertão como seu lugar, seu mundo vivido e experienciado. Esse lugar enquanto mundo vivido do sertanejo não é alheio às agruras do cotidiano duro e ríspido que marca a paisagem rural do sertão.

Contudo, o Estado se interessa pelo sertão como espaço em que se pode colher o alimento material e, indo além, espiritual para a nação, com fortes aspirações capitalistas e como reserva de valor. O sertão da contemporaneidade coloca-se em nossos dias como importante direcionador econômico, social, cultural e de políticas públicas. Antigas regiões de fronteira tornam-se foco do moderno. Além da agroindústria hegemônica, o turismo vem construindo e reconhecendo os espaços rurais como um viés de desenvolvimento socioeconômico para o país com base nos aspectos locais. Porém, é o capital turístico e urbano que se apropria do espaço e do lucro motivado pelo turismo em espaço rural. Hoje, a ideologia do rural permeia a qualidade de vida, o sossego o descanso. 
Longe de findar essa reflexão sobre litoral e sertão, sabe-se que essa dicotomia não será tão cedo um tema ultrapassado. As constantes modificações dos modos de vida e de produção conduz a ideia de sertão numa constante ressignificação com a demanda expansionista do capital no campo e seus "valores" agregados.

A tarefa é árdua. Está posto o desafio de compreender o sertão como lugar indo além dos estereótipos e mitos que o cercam. A paisagem rural e sertaneja espera por olhares que apreendam a condição dialética de um espaço contraditório e dicotômico. A cultura e a construção do lugar dos sujeitos que se reinventam ante a insurgência do capital moderno e articulador da pós - modernidade.

\section{REFERENCIAS}

BRANDÃO, C. R. A partilha da Vida. São Paulo: Cabral Editora, 1995.

BRASIL. Biblioteca Básica Brasileira. História do Brasil 1500-1627 (Frei Vicente do Salvador), 2014. Disponível em: <file:///D:/Assistente/Downloads/5\%C3\%94\%C3\%87\%C3\%B3-Historia-do-Brasil-1500-1627-BBB.pdf>. Acessado em: março de 2016.

CÂNDIDO, A. Os parceiros do rio bonito. Coleção: documentos brasileiros. Livraria J. Olympio Editora. Rio de Janeiro, 1974.

CHAVEIRO, E. F. O Cerrado em disputa: sentidos culturais e práticas sociais contemporâneas. In: ALMEIDA, M. G. de; CHAVEIRO, Eguimar Felício; BRAGA, Helaine Costa (Org.). Geografia e Cultura - os lugares da vida e a vida dos lugares. Goiânia: Editora Vieira, 2008.

CLAVAL, P. As abordagens da Geografia Cultural. CASTRO, I. E.; GOMES, P. C. C.; CORRÊA, R. L. (Org.). Explorações geográficas: percursos no fim do século. Rio de Janeiro: Editora Bertrand Brasil, 1997.

Do olhar Geográfico do Geógrafo a Geografia do olhar dos outros. Conferência proferida na abertura do Evento do NEPEC - Rio de Janeiro, 2002. 
O papel da Nova Geografia Cultural na compreensão da Geografia Humana. In: ROSENDAHL. Z.; CORRÊA, R. L. (Org.). Matrizes da Geografia Cultural. Rio de Janeiro: EdUERJ, 2001.

CORRÊA, R. L. Brasil: Questões Atuais da Reorganização do Território. Rio de Janeiro: Bertrand Brasil, 1996, p. 367-413.

FAUSTO, B. História do Brasil. São Paulo: Editora da USP, 1996.

GOMES, H.; TEIXEIRA NETO, A.; BARBOSA, A. S. Geografia: Goiás-Tocantins. $2^{\circ}$ ed. Goiânia: Editora da UFG, 2004.

MACIEL, D. P. Estado e território na hinterlândia brasileira: as ações da Fundação Brasil Central (FBC) - 1943-1967. In: SILVA, Ademir Luiz da; OLIVEIRA, E. C. de; MELO, M. de (Orgs.). Território, cidades e cultura no cerrado. Anápolis: Universidade Estadual de Goiás, 2012, p. 29-52.

MORAES, A. C. R. Território e História no Brasil. São Paulo: HICITEC, 2002.

MURARI, L. Brasil, ficção geográfica: ciência e nacionalidade no país d'Os sertões. São Paulo: Annablume; Belo Horizonte: Fapemig, 2007.

PERDIGÃO, F.; BASSEGIO, L. Migrantes Amazônicos: Rondônia a trajetória da ilusão. São Paulo: Loyola, 1992.

PALACIN, L. O século do ouro em Goiás. 4º ed. - Goiânia: Ed. UCG, 1994.

MASSEY, D. Pelo Espaço - Uma nova política da espacialidade. Rio de Janeiro: Bertrand Brasil, 2009.

MENDONÇA, M. Os novos movimentos sociais cerradeiros: a territorialização do MAB em Goiás. In: ALMEIDA. M. G. (Org.). Tantos Cerrados. Goiânia: Editora Vieira, 2005. 
Revista de Geografia (Recife) V. 36, No.1, 2019

SANTOS, M. Da totalidade ao lugar. 1. ed., 1. reimp. São Paulo: Editora Edusp, 2008.

TUAN, Yi-Fu. Espaço e lugar: a perspectiva da experiência. São Paulo: Difel, 1983.

SOUZA, C. V. A pátria geográfica: sertão e litoral no pensamento social brasileiro. Goiânia: Editora UFG, 1997.

WAIBEL, L. Capítulos de geografia tropical e do Brasil - Ibge. Rio de Janeiro, 1979. 